\title{
Advancing gene therapies, methods, and technologies for Parkinson's Disease and other neurological disorders
}

\author{
Massimo S. Fiandaca ${ }^{1}$, Russell R. Lonser ${ }^{2}$, J. Bradley Elder ${ }^{2}$, Mirosław Ząbek ${ }^{3}$, Krystof S. Bankiewicz ${ }^{1,2,3}$ \\ ${ }^{1}$ Brain Neurotherapy Bio Inc, Oakland, California, USA \\ ${ }^{2}$ Department of Neurological Surgery, Ohio State University Wexner Medical Centre, Columbus, Ohio, USA \\ ${ }^{3}$ Interventional Neuro Centre (INC), Bródno Mazovia Hospital, Warsaw, Poland
}

\begin{abstract}
Introduction. Vector-based intracerebral gene therapies are being used to treat specific neurodegenerative conditions such as Parkinson's Disease (PD). This review presents a basis for central nervous system (CNS) gene therapy treatments of neurodegenerative diseases such as $\mathrm{PD}$, as well as the need for novel skill sets and health delivery strategies within the clinical neurosciences (neurology and neurosurgery) to meet future demand for such therapies.

State of the art. Preclinical vector-based gene therapy approaches have been translated into clinical trials for PD and other neurodegenerative conditions. Unfortunately, such trials, and parallel efforts using other therapeutics, have yet to provide a breakthrough. Image-guided convection enhanced delivery (CED) optimises the parenchymal distribution of gene therapies applied within the CNS, and may ultimately provide such a breakthrough.

Clinical implications. Currently, image-guided CED and gene therapy are not part of training programmes for most neurosurgeons and neurologists. As a result, few medical centres and hospitals have sufficiently experienced teams to participate in gene transfer clinical trials for PD or other neurological conditions. If CNS gene therapies prove to be efficacious for PD and/or other conditions, the demand for such treatments will overwhelm the available number of experienced clinical neuroscience teams and treatment centres.

Future directions. Expanded indications and demand for CNS gene therapies will require a worldwide educational effort to supplement the training of clinical neuroscience practitioners. Initially, a limited number of Centres of Excellence will need to establish relevant educational training requirements and best practice for such therapeutic approaches. Advanced technologies, including robotics and artificial intelligence, are especially germane in this regard, and will expand the treatment team's capabilities while assisting in the safe and timely care of those afflicted.
\end{abstract}

Key words: gene therapy, convection-enhanced delivery, Parkinson's Disease, clinical neuroscience education, robotics, artificial intelligence

(Neurol Neurochir Pol 2020; 54 (3): 220-231)

\section{Introduction}

The application of novel biological and biophysical knowledge to therapeutic and technological innovations in medicine, especially since around 1990, has provided breakthrough interventions for a variety of neurological conditions previously considered to be untreatable or incapable of being completely treated. Historical indirect (systemic) attempts to provide therapeutic molecular compounds to the central nervous system (CNS) have been restricted by the presence of the blood-brain-barrier (BBB). More direct routes of drug delivery, including drug distribution via cerebrospinal fluid (by lumbar puncture, subarachnoid, drug polymer, or intraventricular delivery) is limited by diffusive properties and non-targeted distribution [1-4]. While providing drug to a targeted CNS site, direct surgical placement of

Address for correspondence: Krystof S. Bankiewicz, Department of Neurological Surgery, Ohio State University Wexner Medical Centre, Columbus, Ohio, USA, e-mail: Krzysztof.Bankiewicz@osumc.edu 
drug-impregnated polymers for treatment of malignant CNS tumour remains limited by diffusional forces at the polymer edge (i.e. the drug only penetrates tissue millimetres from the polymer edge with a steep drop-off in concentration) and tissue injury at the site of placement.

Recently, the successful development of new molecular agents, device innovations, and improved neurosurgical techniques have helped 'unlock' the CNS to direct delivery via infusion, providing a route for the more effective treatment of specific neurological maladies. Consequently, direct intracerebral delivery strategies to the CNS, ones that circumvent the BBB through intraparenchymal CNS infusions, are being employed. For conditions requiring parenchymal penetration of the therapeutic agent, especially in treating distinct, focal targets, direct intraparenchymal delivery is preferred.

Today, more effective direct CNS intraparenchymal distribution of drugs and biologics is being achieved via convection-enhanced delivery (CED) methods, first developed in the early 1990s $[5,6]$. CED uses a constant pressure gradient-dependent bulk flow within the extracellular fluid of the CNS derived from an external pump. This drives both small and large molecular species (including macromolecules and viruses [7]) within the infusate, well beyond the limits of simple diffusion from the site of injection (multiple centimetres rather than millimetres). Bulk flow associated with CED, therefore, transports the infusate homogeneously within a volume of distribution (Vd) that is dependent on the infusion volume $(\mathrm{Vi})$ and the specific tissue characteristics of the target parenchymal volume. CED provides a steep concentration drop at the advancing margin of the convected infusate (Fig. 1).

Such a distribution strategy is ideal for covering a specific parenchymal volume with a homogenous concentration of a therapeutic drug, while limiting such concentrations within the surrounding tissue. Usually, intraparenchymal injection strategies without CED limit their distribution to the end of the injection needle or cannula, within a small cavity, and tend to lose the rest of their Vi to reflux outside the parenchyma, and often into the subarachnoid space. Without or with CED, distribution beyond the infusate margin continues over time, as a result of a constant physiological bulk flow induced by the 'perivascular pump' mechanism [8], as well as by diffusion.

Iterative improvements in convective delivery methodology [9-11], delivery cannula designs $[12,13]$, the safe use of contrast co-infusions for real-time parenchymal CED visualisations [14-17], and intraoperative magnetic resonance imaging (iMRI) [18], have catalysed the development of this unique intracerebral therapeutic direct delivery platform [17, 19], with initial applications focused on neuro-oncology [20-23] and certain inherited neurometabolic disorders [24, 25]. With advances made in gene therapies for treating specific human neurological conditions [26, 27], and specific neurodegenerative diseases [28-30], the same image-guided CED platform has been increasingly called upon in testing CNS gene therapy strategies, including two ongoing Parkinson's Disease (PD) trials [31, 32].

In this review, we will focus on the implications related to these specific PD gene therapies, and gene therapies utilising similar delivery platforms for other selected neurodegenerative conditions.

\section{State of the art}

Although the aetiopathogenesis of most idiopathic neurodegenerative disorders is likely to be due to a combination of genetic predisposition and exposome-induced epigenetic modulation [33], the pathophysiological characteristics associated with the expressed clinical phenotype are well-documented and increasingly understood. Alpha ( $\alpha$ )-synucleinopathies are specific neurodegenerative disorders in which aggregates of $\alpha$-synuclein ( $\alpha$-syn) protein accumulate within neurons, nerve fibres, and glia, with clear evidence of an associated parenchymal cell loss [34]. The three main types of $\alpha$-synucleinopathies include PD, dementia with diffuse Lewy bodies (DLB), and multiple system atrophy (MSA). An important feature of these three neuropathologies is that differential neuronal and glial susceptibilities appear to dictate the eventual phenotypic manifestations and clinical course. PD has both idiopathic and familial/genetic forms, with the latter including mutations/ /alterations involving the SNCA, LRRK2, VPS-35, PARKIN, or PINK1 genes, among others [35].

For this review related to gene therapy, we will focus primarily on idiopathic PD treatment strategies, and introduce recent considerations for MSA. Unfortunately, the primarily genetic forms of $\mathrm{PD}$ have yet to be tested in CNS gene therapy trials.

The idiopathic form of $\mathrm{PD}$ is rare before the age of 50 , its incidence and prevalence progressively increasing after the age of 60 and peaking around the age of 85 , with a male:female ratio of 1.4:1.0 [36]. Nearly 1 million individuals live with PD in the United States (US) in 2020, and there are at least 8-10 million worldwide. Before diagnosis, prodromal PD patients will suffer from a variety of non-motor impairments, including loss or reduction in olfaction, sleep disturbances, constipation, urinary dysfunction, orthostatic hypotension, and depression [37]. At the onset of clinical PD, findings include asymmetric motor disturbances, usually tremor or hyper-rigidity, that gradually evolve to include the cardinal signs of TRAP (Tremor, Rigidity, Akinesia, and Postural instability) with disease progression.

Approved treatments for PD have varied over the years but include both medical and surgical interventions, including but not limited to the use of levodopa (L-dopa), dopamine agonists, stereotactic brain lesioning, and deep brain stimulation (DBS). Most recently, trials testing an anti- $\alpha$-syn antibody have been initiated [38]. While DBS has provided a rational and efficacious symptomatic treatment option for TRAP-related clinical features, the use of DBS has been limited due in part to associated risks and complexities of surgical implantation, 


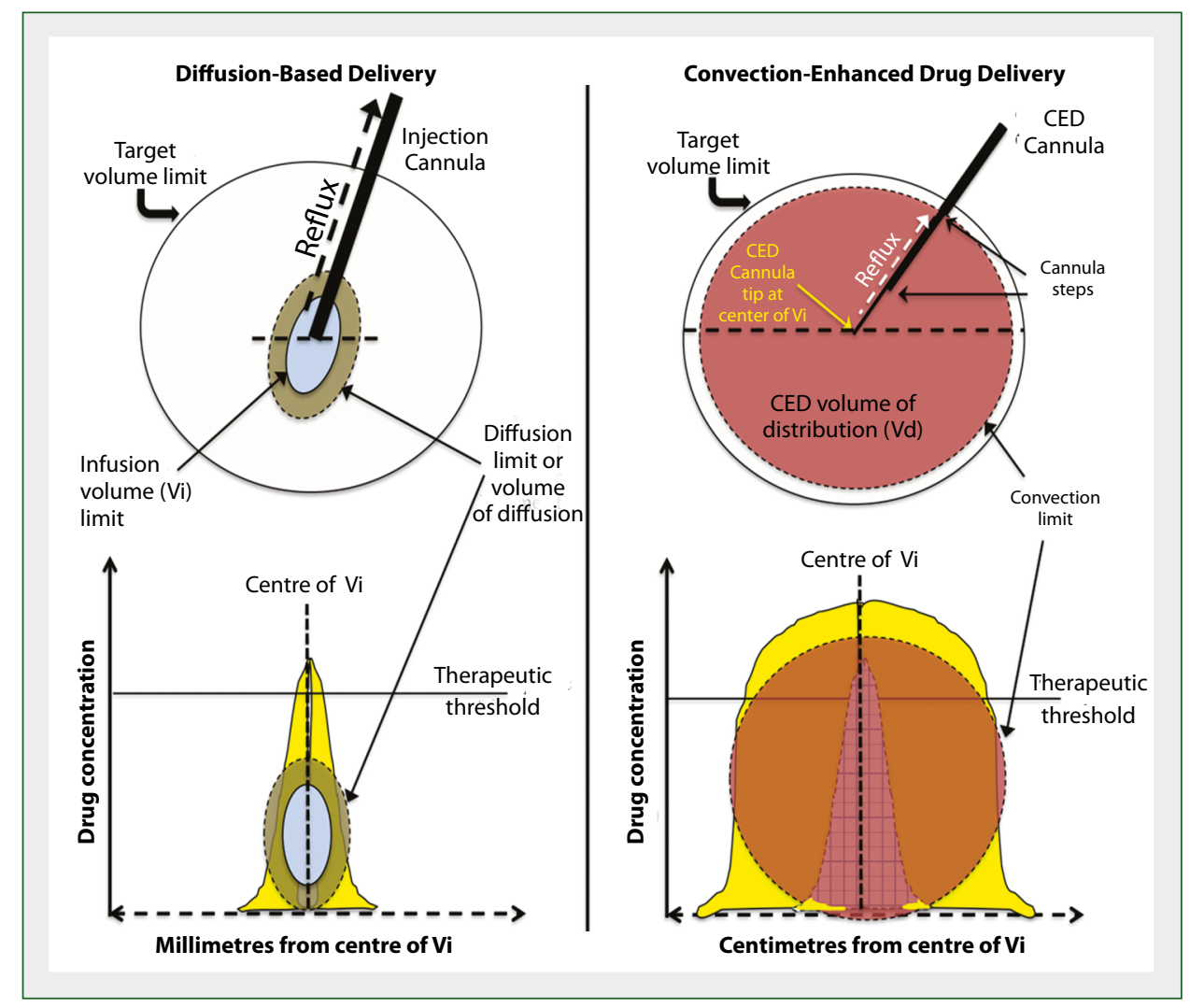

Figure 1. Schematic differences between diffusion-based and convection-enhanced delivery methods within brain parenchyma. Both methods are currently being used to provide therapeutic agents to specific target volumes within the brain.

Left: Diffusion-based drug delivery within brain parenchyma. The top left schematic depicts a typical relatively large bore injection cannula that allows rapid injection of infusate but is associated with relatively large and uncontrolled reflux along the cannula resulting from transient increase in local tissue pressure. The reflux limits the distribution (blue) of the infusion volume (Vi) within the target. Through diffusion (several millimetres), the relatively small residual Vi retained within the target (blue) is able to marginally increase the total brain volume perfused by infusate (grey). Note the depicted insufficient coverage of the target volume. The dashed black line across the diffusion volume, at the tip of the injection cannula, represents the bottom left concentration schematic for diffusion-based delivery. The bottom left schematic portrays the therapeutic concentration of infusate (yellow area under the curve) based on distance from centre of $\mathrm{Vi}$, with an overlay of the limits of $\mathrm{Vi}$ (blue) and diffusion (grey). Note the steep concentration drop to sub-therapeutic threshold levels within short distances from the centre of Vi. Right: Convection-enhanced delivery (CED) within brain parenchyma. The top right schematic portrays CED's smaller bore, reflux-resistant, stepped cannula. The steps on the cannula limit reflux along the cannula track and improve distribution of infusate within the extracellular fluid spaces via bulk flow. Although reflux and distribution beyond the first step, proximal to the cannula tip, allows greater coverage of the target volume, the second step typically prevents reflux along the cannula outside the target. Extracellular bulk flow induced by CED of the Vi provides a significantly larger volume of distribution $(\mathrm{Vd})$ than via diffusion. The dashed black line along the Vd, at the tip of the CED cannula, represents the bottom right concentration schematic for CED-based drug delivery. As depicted in the bottom right schematic, the therapeutic concentration of infusate (yellow area under the curve) with CED extends for centimetres from the centre of Vi, providing a larger, more homogenous concentration of the therapeutic agent within the $\mathrm{Vi}$, up to the convection limit. To contrast the two delivery methods, the diffusion concentration curve is also depicted

device programming, and hardware/maintenance-related complications. In general, PD has a clinical course that extends over many decades. Effective therapeutic approaches differ based on the stage of disease progression.

Within the brains of PD patients, the accumulation of aggregated $\alpha$-syn protein occurs within at-risk nigrostriatal dopaminergic neurons (DANs) and is exemplified by the progressive loss of striatal (primarily putaminal) dopaminergic (DAergic) neurotransmission, dopamine (DA) levels, an imbalance in inhibitory and excitatory signalling to and from the striatum, and the eventual manifestation of the cardinal signs, with worsening disability over time [39]. Early nigrostriatal degeneration features loss of terminal DAergic dendrites and synapses, especially within the dorsolateral putamen, and progressive dysfunction and death of DAergic cell bodies (and their axons) within the substantia nigra pars compacta ( $\mathrm{SNpc}$ ), and to a lesser extent within the adjacent ventral tegmental area (VTA) [40]. 
Up to $25 \%$ of all DANs within the SNpc are estimated to be lost during the five years prior to the clinical onset of $\mathrm{PD}$ motor features, with additional exponential losses (toward $\sim 80 \%$ DAN loss) over the subsequent $15-25$ years [41]. PD features significant neurodegeneration within other important brainstem nuclei, including the dorsal motor nucleus of the vagus, the pedunculopontine nucleus, locus coeruleus, and raphe [42]. Associated noradrenergic and serotonergic losses, together with reduced DAergic expression in cerebrocortical regions (from VTA DAN losses), are likely to impact sleep, mood, and cognition in PD patients. Importantly, however, the direct and indirect striatonigral pathways, originating from medium spiny neurons of the putamen, appear to remain intact in PD [40], and play a critical role in specific gene therapy strategies, as described below.

MSA is a rare $\alpha$-synucleinopathy and neurodegenerative disease characterised by clinically progressive combinations of dysautonomia, pyramidal signs, parkinsonism and/or cerebellar dysfunction. With a prevalence of 3-5 cases per 100,000 population (a total of up to 16,500), MSA meets the criteria of being an orphan disease (a condition affecting $<200,000$ individuals) within the US. The clinical features at presentation are variable, but most MSA patients are categorised by predominant motor signs and segregated into either parkinsonian (MSA-P) or cerebellar (MSA-C) subtypes. Variability within, and overlap between, these two phenotypes is not uncommon, particularly in the later stages of the disease [43]. MSA-P is more prevalent in Western countries, accounting for $60-80 \%$ of MSA cases, whereas MSA-C predominates in Japan [43, 44] and the rest of Asia. The rate of disease progression, from the onset of motor signs, is relatively rapid in MSA cases, with the development of major disability within 3-5 years, death within 8-10 years, and individuals rarely surviving 15 years from diagnosis $[45,46]$. Dysautonomia is an early and pervasive characteristic of both MSA subtypes, often appearing years before the onset of the motor dysfunction [47], and contributing significantly to the progressive disability.

Severe and early-onset of dysautonomia is a predictor of an aggressive disease phenotype [48] and a poorer prognosis [43]. With dysautonomia, MSA patients commonly experience genitourinary, gastrointestinal, and thermoregulatory dysfunctions, all of which have limited therapeutic options. Sleep disturbances are also prevalent in both MSA subtypes, especially rapid eye movement (REM) sleep behavioural disorder, occurring in $70-80 \%$ of MSA patients but in only $50 \%$ of idiopathic PD patients [46]. Like PD, the aetiopathogenesis of MSA remains unclear, despite disease severity being directly related to the extent and burden of $\alpha$-syn accumulations within glial (oligodendroglial) cells. Glial cytoplasmic inclusions (GCIs), composed of aggregated $a$-syn and phosphorylated a-syn $[49,50]$, are found within affected oligodendroglia. Concentrations of GCIs are especially profound within the putamen and substantia nigra of MSA patients [49, 51-53].
One proposed mechanism for the associated neurodegeneration seen in MSA is the loss of neurotrophic support of central catecholaminergic neurons, as evidenced by significant loss of GDNF protein in the frontal cortex and cerebellum [54], as well as within the putamen [55]. Oligodendroglia are a key source of growth factors [56], including the production of GDNF, which is critical for the maintenance of adult catecholaminergic neurons [57]. Putaminal levels of GDNF and DA are significantly reduced in autopsied MSA patients compared to controls [55]. Such reduced GDNF levels may either result from striatal GCIs impairing the function of intrinsic neuronal populations known to produce GDNF, or from a primary loss of GDNF production within the striatum that leads to the focal accumulation of GCIs. The nigrostriatal pathway physiology is significantly altered under both proposed mechanisms, with a reduction in striatal GDNF and its trophic influence on DAN terminals. In either case, the DAergic dendrites within the putamen respond to the low intrinsic levels of GDNF by becoming 'sick but not dead' [55], reducing local DA levels, until eventually degenerating due to lack of trophic support. Under such circumstances, nigrostriatal DAergic axons undergo similar responses to reduced striatal or local oligodendroglial GDNF production.

Finally, nigral DAergic neuronal somata may be negatively influenced by lack of local oligodendroglial GDNF support and/or the negative influences provided by degenerating axon terminals within the putamen. Such nigrostriatal dysfunction is believed to result in prominent parkinsonian clinical features, as noted especially in MSA-P. The loss of oligodendroglial neurotrophic support resulting from GCIs may not only suppress nigrostriatal DAergic function, therefore, but may negatively influence other central catecholaminergic networks (noradrenergic, serotonergic), providing a basis for the evolving dysautonomia. There are currently no specific treatment options for MSA other than those directed toward temporary symptomatic relief.

Methods for replenishing the brain's neurotrophic environment in PD with direct GDNF protein delivery have been translated to the clinic, since systemic administration was unsuccessful in crossing the BBB. Initial investigations featured the use of serial, monthly intracerebroventricular infusions of recombinant GDNF protein (rGDNF) of varying doses via an implanted catheter system [58]. This randomised, double-blind, placebo-controlled trial, evaluating escalating doses of rGDNF versus placebo, in 50 subjects treated for eight months, showed no therapeutic efficacy. Probably, this lack of efficacy resulted from rGDNF not reaching the intended target structures (putamen and/or substantia nigra) in effective levels when delivered within the CSF, and as shown in other intracerebroventricular protein infusion studies [1], while activity of rGDNF was determined in subjects experiencing adverse events, especially at higher protein doses delivered. Almost concurrently, initial intraparenchymal rGDNF infusions for PD were tested [59]. Intraputaminal stereotactic delivery cannulas 
delivered rGDNF continuously $(0.01 \mu \mathrm{g} \mathrm{rGDNF} / \mu \mathrm{L}$ infusate; 10.8-14.4 $\mu \mathrm{g} \mathrm{rGDNF/putamen/day)} \mathrm{over} 12$ months [60], or via an intermittent delivery protocol $(0.02 \mu \mathrm{g} \mathrm{rGDNF} / \mu \mathrm{L}$ infusate; $120 \mu \mathrm{g} r \mathrm{rDNF} /$ putamen/4 weeks) for 40 weeks [61]. Although the safety and tolerability of the delivered rGDNF within the brain parenchyma was confirmed, and early signs of efficacy were suggested, a more recent single-centre, randomised, double-blind, placebo-controlled trial and trial extension failed to meet the primary trial endpoint $[61,62]$. The authors interpreted their results as suggesting a greater likelihood of rGDNF infusion efficacy in a proposed intermittent (single dose delivered every four weeks) delivery Phase 3 trial, by extending treatment and clinical assessment from baseline to 80 weeks, and providing a higher rGDNF dose (up to $0.06 \mu \mathrm{g}$ GDNF protein/ $\mu$ L infusate) [62].

The problem of demonstrating the efficacy of GNDF protein infusion in PD trials over nearly two decades has resulted in pessimism directed towards additional therapeutic investigations utilising GDNF for the treatment of PD. Despite the proposed changes to the protocol for their forthcoming rGDNF Phase 3 trial, we believe there might be other technical issues to consider, based on the described delivery protocol [61], that might ultimately affect the trial's efficacy.

First and foremost, the delivery of rGDNF within the putamen (and CNS), using either continuous or intermittent infusion methods, has yet to be confirmed using contrast co-infusion and real-time MRI. Without such confirmation, the degree of on-target distribution and cannula reflux cannot be accurately predicted. Importantly, a reflux-resistant cannula was not utilised in any of the rGDNF infusion studies to date. Although utilising $2 \mathrm{mM}$ gadolinium test infusions, and CED infusion rates [9], there is a lack of data confirming that the cannula systems and pumps used actually provide convective flow and distribution [60-62]. Additionally, intermittent intraparenchymal delivery of rGDNF is known to provide concentration peaks and an exponential drop-off to below baseline levels within days to a few weeks following administration [63]. A 4-week delivery strategy for rGDNF would be associated with significant periods of time with subthreshold neurotrophic levels. Finally, we and others strongly believe that effective Vd is highly dependent on the Vi delivered, especially when using CED. Based on known human putaminal volumes [64], the percentage coverage of the estimated putaminal volume, following a known $\mathrm{Vi}$ (in gene therapies and rGDNF infusion studies), with and without CED ([31, 32, 65-68], and clinicaltrials.gov: NCT00985517, NCT01621581, NCT01973543, NCT02418598, NCT03065192), suggest a Vi of $\geq 1,800 \mu \mathrm{L}$ is required to achieve $\mathrm{a} \geq 50 \%$ putaminal $\mathrm{Vd}$ (Fig. 2). Unless abnormal brain anatomy and physiology are present [69], such a Vi, if convected over 4-7 hours, has been well tolerated [31].

There is growing clinical evidence of viral vector-based gene therapy approaches for delivering beneficial transgenes to the brains of PD patients [70,71]. After being effectively developed in animal models and eventually translated to the clinic, two primary viral vectors have proved most useful and safe, based on either the adeno-associated virus (AAV) [72] or lentivirus (Lenti) [73]. The AAV serotype 2 (AAV2) has a preferential affinity to neurons [15], raising its relevance when targeting putamen and other neuronal populations in the CNS, and limiting transduction of glia and other non-neuronal cells. Lenti vector tropism can be specifically engineered through pseudotyping strategies [74]. Both AAV2 and Lenti vectors have been employed to deliver relevant genetic payloads for treating PD to the human putamen. Small- and medium-sized spiny GABAergic neurons, making up $95 \%$ of putaminal neuronal populations [75], are the primary targets of transduction for both AAV2 and Lenti vectors delivered within that subcortical structure. These neuron populations are not typically associated with degeneration in PD, but are affected in MSA-P where caudal and dorsolateral populations of putaminal medium spiny neurons are severely depleted [76]. AAV2 has also been used in PD trials in attempts to influence the subthalamic nucleus, caudate, and substantia nigra $[70,71]$. Currently active putaminal enzyme replacement strategies for PD utilise either AAV2 or Lenti, based on the size of the genetic payload being delivered. AAV vectors are most effective in packaging single stranded transgenes of less than 5 kilobases (kb) [77], approximating the size of the wild type viral genome, while Lenti vectors permit packaging of nearly double the payload of AAV [78]. PD trials replacing depleted aromatic amino acid decarboxylase (AADC) alone have utilised AAV2 constructs (AAV2-AADC) $[31,66,79,80]$, while those using Lenti vectors have delivered a trio of transgenes coding for AADC, tyrosine hydroxylase $(\mathrm{TH})$ and GTP-cyclohydrolase 1 (GCH1) to augment dopamine production [81]. Both approaches have focused on replacing lost dopamine production capacity seen in the latter stages of $\mathrm{PD}$ and allowing titration of putaminal dopamine levels by altering the amount of precursor medication (L-dopa) taken. Nonhuman primate parkinsonian models have shown strong AADC expression in transduced putamen, with 10-to-20-fold improvements in behavioural responses to L-dopa medication $[82,83]$. Since inception, the AAV2-AADC gene therapy for PD has primarily utilised our iMRI CED platform to gradually increase the delivered Vi to enhance putaminal transduction volume [31,80], and is now delivering up to $1,800 \mu \mathrm{L}$ per putamen. Using the same AAV2-AADC therapeutic delivered via a larger Vi alone (see Fig. 2G vs Fig. 2H), was associated with improved clinical results [31]. Similar iterations and detailed assessments of the Lenti tricistronic vector deliveries are not yet available [81]. Both strategies are progressing towards later stage investigations for efficacy, having shown safety and tolerability over many years.

A PD gene therapy abandoned in 2012, that attempted to suppress subthalamic nucleus (STN) activity with an AAV2 vector carrying the glutamic acid decarboxylase (GAD) gene (AAV2-GAD), provided clinical benefits that were no 


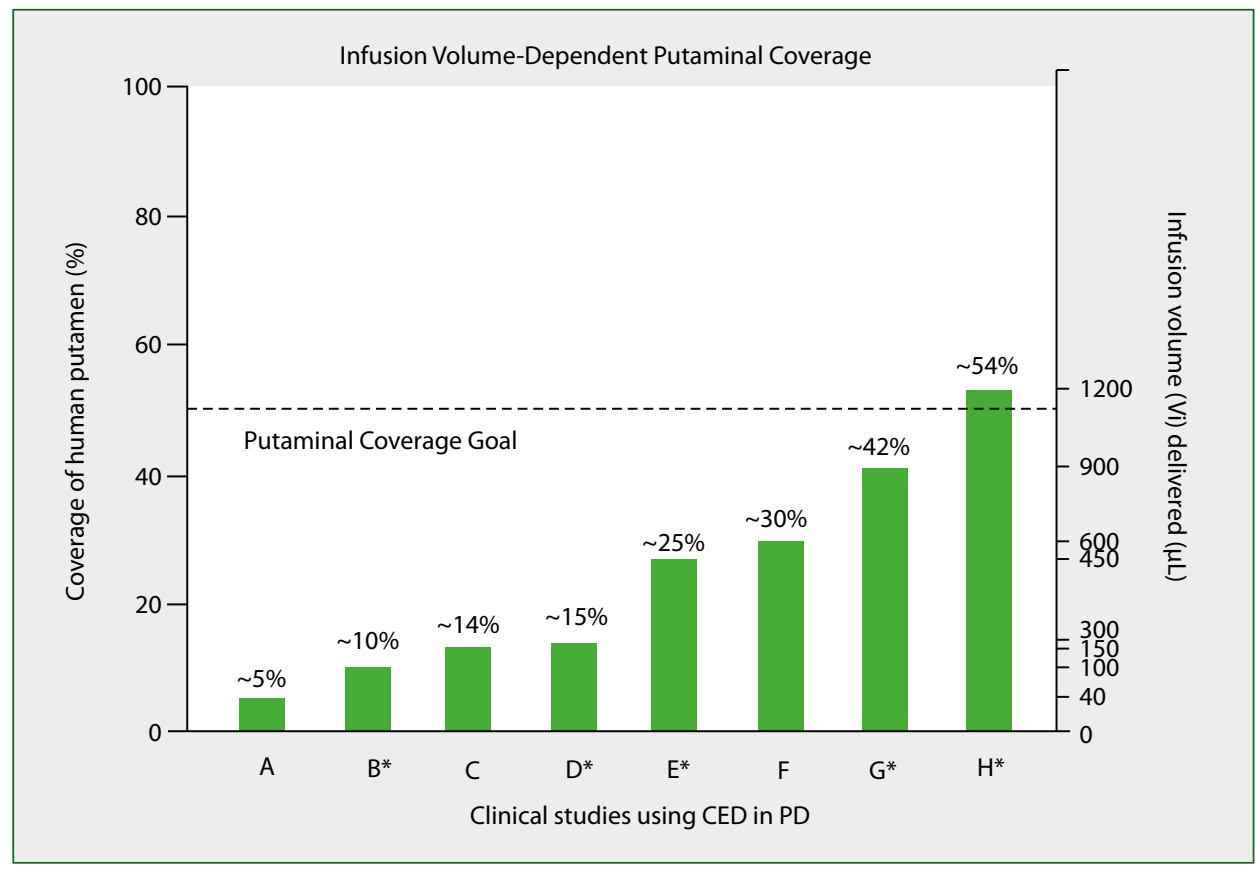

Figure 2. Infusion volume (Vi)-dependent putaminal coverage. This bar chart represents collected data from past putaminal infusion investigations, without or with CED, as described in the text. Left vertical axis presents the estimated volumetric putaminal coverage determined from a particular study, as a percentage of normal human putaminal volume (see [64]). Putaminal coverage percentage for each study is shown above the individual bar graphs. The right vertical axis presents the reported Vi in microlitres $(\mu \mathrm{L})$. Labels A-H on the horizontal axis correspond to depicted data from a publication, clinicaltrials.gov site, or a scientific presentation. An asterisk $\left({ }^{*}\right)$ beside the letter indicates reported use of a CED platform, including contrast co-infusion and real-time iMRI monitoring. A) from [67] - 2010 AAV2-NRTN trial report; B) from [66] - 2012 AAV2-AADC trial report, and NCT02418598; C) from [67, 68] - 2013 and 2020 AAV2-NRTN trial reports, and NCT00985517; D) from AAV2-AADC infusion trial - NCT02418598; E) from [32] - 2019 AAV2-GDNF trial report, NCT01621581 and NCT01973543; F) from [61, 62] - 2019 rGDNF intermittent infusion trial reports; G) from AAV2-AADC infusion trial - NCT03065192; H) from [31] 2019 AAV2-AADC infusion trial report.

CED - convection-enhanced delivery; iMRI - intraoperative magnetic resonance imaging; AAV2 - adeno-associated virus, serotype 2; NRTN - neurturin; AAV2-NRTN - AAV2 vector carrying the NRTN gene; AADC - aromatic amino acid decarboxylase; AAV2-AADC - AAV2 vector carrying the AADC gene; NCT - national clinical trials number; GDNF - glial cell-derived neurotrophic factor; AAV2-GDNF - AAV2 vector carrying the GDNF gene; rGDNF - recombinant GDNF protein

better than DBS $[84,85]$. A recent analysis of brain scan data from these trials [86], however, has encouraged a company to acquire the rights to this therapeutic approach. Unfortunately, significant limitations exist in terms of the number of subjects analysed. This approach will probably require a costly Phase 3 trial to provide evidence of efficacy.

Two neurotrophic factor gene therapies delivered via AAV2 vectors have provided either neurturin (AAV2-NRTN) or glial cell-line derived neurotrophic factor (AAV2-GDNF) to subjects with PD. Additional AAV2-NRTN trials have been abandoned due to failure to meet primary endpoints in two double-blind placebo-controlled studies, both of which targeted the bilateral putamen and one of which also infused the substantia nigra $[65,87]$. Importantly, the AAV2-NRTN trials confirmed the safety of delivering growth factors to the putamen and substantia nigra [88], pathologically confirmed transduction limits using small parenchymal delivered $\mathrm{Vi}$, especially without CED and optimised delivery technologies
[68, 89-91], and suggested evidence that neurotrophic factor gene therapy may be more effective in earlier than later PD stages $[87,92]$. The remaining neurotrophic factor gene therapy trial results in advanced PD, using AAV2-GDNF in a Phase 1 open-label study (NCT01621581), were recently published [32]. All treated subjects tolerated their iMRI CED procedure and three escalating vector doses without significant adverse events. Importantly, all 13 subjects treated are now over 36 months and some over 60 months post-op, and show a) stability of their clinical motor exams and activities of daily living, b) stability of their levodopa-equivalent daily doses, and c) significant increases in their fluorodopa positron emission tomography (PET) imaging signals at the infusion sites, when comparing baseline to the 6- and 18-month treatment intervals. The study had a Vi of $450 \mu \mathrm{L}$ per putaminal target and was determined by iMRI to provide an average of $26 \%$ coverage. An upcoming Phase $1 \mathrm{~b}$ trial (NCT04167540) for 12 PD subjects, due to start in 2020, will test lessons learned from previous 
gene therapy investigations. The open-label Phase $1 \mathrm{~b}$ trial will test earlier stage $(n=6)$ compared to moderate to advanced stages $(n=6)$ of $P D$, anticipating greater potential efficacy for GNDF effects in the former group compared to the latter, based on residual nigrostriatal DANs [41], and preclinical [93] and clinical $[87,92]$ opinions advanced. This trial will also test the highest ever approved dose of AAV2-GDNF vector, not tested in the Phase 1 trial due to limited putaminal coverage (26\%) attained using that protocol, and distributing a similar Vi (up to $1,800 \mu \mathrm{L}$ per putamen) with surgical methods (single occipital longitudinal trajectory spanning each putamen) $[11,94]$ currently preferred in the AAV2-AADC gene therapy study (NCT03733496) [31]. As mentioned earlier in this review, the specific AAV2-GDNF vector delivered to the putamen in previous and current PD trials avails itself of the persistent striatonigral projections and anterograde transport provided by that particular AAV2 vector. Such capabilities allow GDNF trophic support to the at-risk putaminal DAN terminals as well as the DAergic somata that are 'sick but not dead' within the SNpc. The more residual nigrostriatal DANs present, the more robust the GDNF-induced upregulation and sprouting [93].

\section{Clinical implications}

There are specific clinical implications related to novel treatments for neurodegenerative diseases such as PD and MSA, as well as a hereditary paediatric orphan disease with a genetic defect tied to catecholaminergic deficiencies (AADC-deficiency; AADC-d) [95]. AAV2-AADC gene therapy for $\mathrm{PD}$ is on track to provide therapeutic relief and mitigation of specific clinical features in subjects that would also be candidates for DBS surgery. Both AAV2-AADC and DBS, however, are not likely to influence the progressively downhill course of PD's nigrostriatal degeneration and mounting therapeutic sequelae that increase disability and shorten the lifespan of those afflicted. AADC gene therapy, however, has provided evidence of the ability to restore DA production, and some clinical benefit, when coupled to peripheral substrate (L-dopa) administration. The utility of AADC gene therapy in PD has encouraged use in AADC-d, where widespread loss of central and peripheral catecholaminergic production due to a genetic defect results in loss of intracellular AADC enzyme function and significantly impaired newborns, children and a few adults. AAV2-AADC gene therapy is currently being tested for AADC-d by two treatment teams, with one team targeting the putamen ([96]; NCT01395641 and NCT02926066) and the other focusing on the midbrain (NCT02852213). Both approaches are currently trying to restore DAergic tone in the afflicted children, and results remain preliminary at this point.

However, it is clear that additional measures will be required to replenish additional catecholaminergic centres within the CNS affected by this genetic defect. With regards to the upcoming PD trial set to test intermittent parenchymal delivery of higher doses of rGDNF over a longer time period, we anticipate limited efficacy due to: 1) a lack of documented infusate distribution and infusion reflux assessment by contrast co-infusion and real-time MRI; 2) the rapid exponential loss of infused rGDNF from the parenchyma resulting in subthreshold GDNF levels shortly after infusion and for a significant period prior to the subsequent (every four weeks) treatment; 3 ) the inability of rGDNF infused within the striatum to influence distal targets such as the SNpc DAergic somata; and 4) the predisposition to infection and mechanical problems associated with the required indwelling devices currently necessary for such chronic treatments. We project that using a single putaminal AAV2-GDNF gene therapy treatment for PD may obviate the need for chronic infusions of rGDNF. AAV2-GDNF gene therapy, using the verified delivery platform, has the capacity to restore constitutive, higher than baseline, levels of parenchymal GDNF within the striatum, and through striatonigral anterograde transport of the AAV2-GDNF vector, to SNpc, as defined in animal models [63, 93, 97].

We expect that a single gene therapy procedure should provide life-long transduction of target cells, and parenchymal trophic factor expression, as has been noted over at least eight years in both non-human primates [97] and humans [68]. In an alternative to antibody-based $\alpha$-syn clearance for human PD [38], rodent investigations [98] suggest that AAV2-GDNF vector reduced the $a$-syn deposit burden in substantia nigra of aged mice, signifying that gene therapy-derived GDNF might mitigate the underlying neuropathology seen in synucleinopathies like PD and MSA. Although MSA-P has yet to be treated, therapeutic intervention using AAV2-GDNF gene therapy is currently being considered. Although the parkinsonian motor features in PD and MSA-P may benefit from AAV2-GDNF putaminal gene therapy, it remains to be seen whether the many debilitating non-motor features will also show relevant responses to treatment.

Current and future investigations will include assessment tools to determine beneficial responses in specific non-motor conditions.

\section{Future directions}

The variabilities inherent within human investigations in clinical medicine make predicting success for any novel therapy a foolhardy undertaking.

With humility, however, we anticipate that efficacious GDNF gene therapy clinical trial results, for either or both PD and MSA, will significantly increase demand for such treatments worldwide. We and others [99] believe, however, that improving gene therapy vector delivery within the CNS remains essential for proper testing of therapeutic efficacy. Optimised delivery strategies, including CED contrast co-infusions, real-time iMRI, and using increased $\mathrm{Vi}$, provide safe and effective distribution methodologies, but allow the 
confirmation of target coverage and off-target distribution that may impact upon clinical results.

Current neurosurgical manpower is less than 4,000 in the US [100] and approaches 50,000 worldwide [101], with markedly fewer individuals experienced in the methods and technologies described in this review. Addressing this shortfall will require the expansion of educational/training opportunities for current neurosurgeons (and neurologists), and the augmentation of tailored training programmes related to specific surgical and neurological management capabilities. Although both neurosurgeons and neurologists currently train in a variety of neuromodulation approaches, only a limited number of specialty training programmes provide trainees with the experience required to deliver safe and effective CED therapeutic interventions. Gene therapy methods to treat specific CNS disorders continue to evolve, with an emphasis on a) training and sufficient numbers of clinical providers, b) being guided by evidence-based medicine, and c) considering the development of Centres of Excellence to specifically advance such treatment opportunities. Such advances will be critical to the safe, efficacious, and standardised evolution of CNS gene therapies.

The future of effective gene therapy treatments for PD, MSA-P, and other CNS conditions, will feature CED platforms that avail themselves of growing iMRI capabilities in medical universities and hospitals. Supplements to the future neurosurgical armamentarium in meeting increased demand for such treatments will feature robotics and advanced technologies in the operating room [102-104] and artificial intelligence (AI) $[105,106]$ to improve the practitioner's accuracy and speed of clinical diagnoses, presurgical and surgical planning, outcome predictions, and overall management.

We await the results of forthcoming clinical trials to implement these and other strategies, focusing on safety and efficacy measures as we seek to improve the clinical trajectories in neurodegenerative and other CNS diseases with gene therapies.

Ethical permissions: Ethical approval was not required for this invited review article.

Conflicts of interest: Massimo S. Fiandaca is a scientific co-founder and Vice President, Clinical Affairs for Brain Neurotherapy Bio Inc. (BNB), a biotechnology company established to advance direct brain delivery strategies, technologies, and gene therapies for neurological diseases. BNB and Dr. Fiandaca are sponsoring a Parkinson's Disease (PD) Phase 16 gene therapy clinical trial testing AAV2-GDNF at two sites: Ohio State University (OSU) and the University of California San Francisco (UCSF). Dr. Fiandaca denies other potential conflicts of interest.

Russell R. Lonser is a scientific co-founder of BNB. He is Chairman of the Department of Neurological Surgery at OSU and oversees all neurosurgical care at that institution, including the BNB-sponsored PD Phase 16 gene therapy clinical trial testing AAV2-GDNF. Dr. Lonser is co-inventor of a patent for imaging delivery of therapeutic agents in the central nervous system (CNS). He has been a neurosurgical consultant at the
Interventional Neuro Centre (INC) Bródno Mazovia Hospital, Warsaw, Poland. Dr. Lonser denies any other potential conflicts of interest.

J. Bradley Elder is an OSU Department of Neurological Surgery faculty member and principal investigator for the PD Phase $1 \mathrm{~b}$ gene therapy clinical trial testing AAV2-GDNF. Dr. Elder has been a neurosurgical consultant at the INC Bródno Mazovia Hospital, Warsaw, Poland. Dr. Elder denies any other potential conflicts of interest.

Miroslaw Zabek is co-founder of the INC Bródno Mazovia Hospital, Warsaw, Poland and serves as Chairman of Neurosurgery at that institution. Along with Dr. Bankiewicz, he has been an active clinical investigator of a variety of neurosurgical procedures introduced to the INC Bródno, including DBS for PD and other movement disorders, and the compassionate treatment of $A A D C$ deficiency subjects using $A A D C$ gene therapy via convection-enhanced delivery (CED). Dr. Zabek has recently gained ethics committee approval at the INC Bródno for the compassionate treatment of subjects with MSA using GDNF gene therapy. Dr. Zabek denies any other potential conflicts of interest. Krystof S. Bankiewicz is founder, Chairman, and Chief Executive Officer of BNB, in addition to co-founding the INCs at UCSF and the Bródno Hospital. Dr. Bankiewicz has also co-founded other therapeutic brain delivery companies, including MedGenesis Therapeutix (advancing rGDNF infusion) and Voyager Therapeutics (advancing AADC gene therapy for PD). He has multiple patents related to direct brain delivery to the CNS, including for gene therapy, as well as for the associated methodologies, delivery devices, and technologies to enhance such therapeutic distributions in a variety of neurological conditions. Dr. Bankiewicz has a funded clinical trial investigating treatment of $A A D C$ deficiency subjects using $A A D C$ gene therapy at UCSF and OSU. BNB and Dr. Bankiewicz are sponsors of the Parkinson's Disease Phase $1 \mathrm{~b}$ gene therapy clinical trial testing AAV2-GDNF at OSU and UCSF. Dr. Bankiewicz denies any other potential conflicts of interest.

Contributors: All authors contributed to the final version of this invited review article, including but not limited to writing, research, editing, and finalising the text and figures. All authors approve the submitted version of the review article for publication.

\section{References}

1. Ziegler RJ, Salegio EA, Dodge JC, Bringas J, Treleaven CM, Bercury $\mathrm{SD}$, et al. Distribution of acid sphingomyelinase in rodent and non-human primate brain after intracerebroventricular infusion. Exp Neurol. 2011;231:261-71. doi: 10.1016/j.expneurol.2011.06.019.

2. Salegio EA, Samaranch L, Jenkins RW, Clarke CJ, Lamarre C, Beyer $J$, et al. Safety study of adeno-associated virus serotype 2-mediated human acid sphingomyelinase expression in the nonhuman primate brain. Human gene therapy. 2012;23:891-902. doi: 10.1089/ hum.2012.052.

3. Samaranch L, Salegio EA, San Sebastian W, Kells AP, Bringas JR, Forsayeth J, et al. Strong cortical and spinal cord transduction after AAV7 and AAV9 delivery into the cerebrospinal fluid of nonhu- 
man primates. Hum Gene Ther. 2013;24:526-32. doi: 10.1089/ hum.2013.005.

4. Passini MA, Bu J, Richards AM, Treleaven CM, Sullivan JA, O'Riordan $\mathrm{CR}$, et al. Translational fidelity of intrathecal delivery of self-complementary AAV9-survival motor neuron 1 for spinal muscular atrophy. Hum Gene Ther. 2014;25:619-30. doi: 10.1089/hum.2014.011.

5. Bobo RH, Laske DW, Akbasak A, Morrison PF, Dedrick RL, Oldfield EH. Convection-enhanced delivery of macromolecules in the brain. Proc Natl Acad Sci U S A. 1994;91:2076-80. doi: 10.1073/pnas.91.6.2076.

6. Morrison PF, Laske DW, Bobo H, Oldfield EH, Dedrick, R.L. High-flow microinfusion: tissue penetration and pharmacodynamics. American Journal of Physiology. 1994;266:R292-R305. doi: 10.1152/ ajpregu.1994.266.1.R292.

7. Szerlip NJ, Walbridge S, Yang L, Morrison PF, Degen JW, Jarrell ST, et al. Real-time imaging of convection-enhanced delivery of viruses and virus-sized particles. J Neurosurg. 2007;107:560-7. doi: 10.3171/ JNS-07/09/0560.

8. Hadaczek P, Yamashita Y, Mirek H, Tamas L, Bohn MC, Noble C, et al. The "perivascular pump" driven by arterial pulsation is a powerful mechanism for the distribution of therapeutic molecules within the brain. Mol Ther. 2006;14:69-78. doi: 10.1016/j.ymthe.2006.02.018.

9. Chen MY, Lonser RR, Morrison PF, Governale LS, Oldfield EH. Variables affecting convection-enhanced delivery to the striatum: a systematic examination of rate of infusion, cannula size, infusate concentration, and tissue-cannula sealing time. J Neurosurg. 1999;90:315-20. doi: 10.3171/jns.1999.90.2.0315.

10. Lonser RR, Sarntinoranont M, Morrison PF, Oldfield EH. Convection-enhanced delivery to the central nervous system. J Neurosurg. 2015;122:697-706. doi: 10.3171/2014.10.JNS14229.

11. Sudhakar V, Naidoo J, Samaranch L, Bringas JR, Lonser RR, Fiandaca MS, et al. Infuse-as-you-go convective delivery to enhance coverage of elongated brain targets: technical note. J Neurosurg. 2019:1-8 (ahead of print). doi: 10.3171/2019.4.JNS19826.

12. Rosenbluth KH, Luz M, Mohr E, Mittermeyer S, Bringas J, Bankiewicz KS. Design of an in-dwelling cannula for convection-enhanced delivery. J Neurosci Methods. 2011;196:118-23. doi: 10.1016/j. jneumeth.2010.12.022.

13. Krauze MT, Saito R, Noble C, Tamas M, Bringas J, Park JW, et al. Reflux-free cannula for convection-enhanced high-speed delivery of therapeutic agents. J Neurosurg. 2005;103:923-9. doi: 10.3171/ jns.2005.103.5.0923.

14. Croteau D, Walbridge S, Morrison PF, Butman JA, Vortmeyer AO, Johnson $D$, et al. Real-time in vivo imaging of the convective distribution of a low-molecular-weight tracer. J Neurosurg. 2005;102:90-7. doi: 10.3171/jns.2005.102.1.0090.

15. Fiandaca MS, Varenika V, Eberling J, McKnight T, Bringas J, Pivirotto $P$, et al. Real-time MR imaging of adeno-associated viral vector delivery to the primate brain. Neuroimage. 2009;47 Suppl 2:T27-35. doi: 10.1016/j.neuroimage.2008.11.012.

16. Su X, Kells AP, Aguilar-Salegio E, Richardson RM, Hadaczek P, Beyer $J$, et al. Real-time MR imaging with gadoteridol predicts distribution of transgenes after convection-enhanced delivery of AAV2 vectors. Mol Ther. 2010;18:1490-5. doi: 10.1038/mt.2010.114.

17. Richardson RM, Kells AP, Rosenbluth KH, Salegio EA, Fiandaca MS, Larson PS, et al. Interventional MRI-guided Putaminal Delivery of AAV2-GDNF for a Planned Clinical Trial in Parkinson's Disease. Mol Ther. 2011;19:1048-57. doi: 10.1038/mt.2011.11.

18. Han SJ, Bankiewicz K, Butowski NA, Larson PS, Aghi MK. Interventional MRI-guided catheter placement and real time drug delivery to the central nervous system. Expert Rev Neurother. 2016;16:635-9. doi: 10.1080/14737175.2016.1175939.

19. Fiandaca MS, Forsayeth JR, Dickinson PJ, Bankiewicz KS. Image-guided convection-enhanced delivery platform in the treatment of neurological diseases. Neurotherapeutics : the journal of the American Society for Experimental NeuroTherapeutics. 2008;5:123-7. doi: 10.1016/j.nurt.2007.10.064.

20. Murad GJ, Walbridge S, Morrison PF, Garmestani K, Degen JW, Brechbiel MW, et al. Real-time, image-guided, convection-enhanced delivery of interleukin 13 bound to pseudomonas exotoxin. Clin Cancer Res. 2006;12:3145-51. doi: 10.1158/1078-0432.CCR-05-2583.

21. Lonser RR, Warren KE, Butman JA, Quezado Z, Robison RA, Walbridge $S$, et al. Real-time image-guided direct convective perfusion of intrinsic brainstem lesions. Technical note. J Neurosurg. 2007;107:190-7. doi: 10.3171/JNS-07/07/0190.

22. Murad GJ, Walbridge S, Morrison PF, Szerlip N, Butman JA, Oldfield EH, et al. Image-guided convection-enhanced delivery of gemcitabine to the brainstem. J Neurosurg. 2007;106:351-6. doi: 10.3171/jns.2007.106.2.351.

23. Fiandaca MS, Berger MS, Bankiewicz KS. The use of convection-enhanced delivery with liposomal toxins in neurooncology. Toxins. 2011;3:369-97. doi: 10.3390/toxins3040369.

24. Lonser RR, Schiffman R, Robison RA, Butman JA, Quezado Z, Walker $\mathrm{ML}$, et al. Image-guided, direct convective delivery of glucocerebrosidase for neuronopathic Gaucher disease. Neurology. 2007;68:25461. doi: 10.1212/01.wnl.0000247744.10990.e6.

25. Salegio EA, Kells AP, Richardson RM, Hadaczek P, Forsayeth J, Bringas $\mathrm{J}$, et al. Magnetic resonance imaging-guided delivery of adeno-associated virus type 2 to the primate brain for the treatment of lysosomal storage disorders. Human Gene Therapy. 2010;21:1093-103. doi: 10.1089/hum.2010.040.

26. Fiandaca MS, Mahapatra S, De Silva S, Bowers WJ, Federoff HJ. Gene therapy for neurological diseases. In: Templeton NS, editor. Gene and Cell Therapy-Therapeutiic Mechanisms and Strategies. 4th ed. Abingdon, UK: CRC Press; 2015. p. 1171-216. doi: 10.1201/ b18002.

27. Simonato M, Bennett J, Boulis NM, Castro MG, Fink DJ, Goins WF, et al. Progress in gene therapy for neurological disorders. Nat Rev Neurol. 2013;9:277-91. doi: 10.1038/nrneurol.2013.56.

28. Sudhakar V, Richardson RM. Gene Therapy for Neurodegenerative Diseases. Neurotherapeutics : the journal of the American Society for Experimental NeuroTherapeutics. 2019;16:166-75. doi: 10.1007/ s13311-018-00694-0.

29. Tuszynski MH. Growth-factor gene therapy for neurodegenerative disorders. Lancet Neurol. 2002;1:51-7. doi: 10.1016/s1474. 4422(02)00006-6.

30. O'Connor DM, Boulis NM. Gene therapy for neurodegenerative diseases. Trends in molecular medicine. 2015;21:504-12. doi: 10.1016/j. molmed.2015.06.001.

31. Christine CW, Bankiewicz KS, Van Laar AD, Richardson RM, Ravina B, Kells AP, et al. Magnetic resonance imaging-guided phase 1 trial of putaminal AADC gene therapy for Parkinson's disease. Ann Neurol. 2019;85:704-14. doi: 10.1002/ana.25450.

32. Heiss JD, Lungu C, Hammoud DA, Herscovitch P, Ehrlich DJ, Argersinger DP, et al. Trial of magnetic resonance-guided putaminal gene therapy for advanced Parkinson's disease. Mov Disord. 2019;34:1073-8. doi: $10.1002 / m d s .27724$.

33. Fiandaca MS, Mapstone M, Connors E, Jacobson M, Monuki ES, Malik S, et al. Systems healthcare: a holistic paradigm for tomorrow. BMC systems biology. 2017;11:142. doi: 10.1186/s12918-017-0521-2. 
34. McCann H, Stevens CH, Cartwright H, Halliday GM. alpha-Synucleinopathy phenotypes. Parkinsonism Relat Disord. 2014;20 Suppl 1:S627. doi: 10.1016/S1353-8020(13)70017-8.

35. Hernandez DG, Reed X, Singleton AB. Genetics in Parkinson disease: Mendelian versus non-Mendelian inheritance. J Neurochem. 2016;139 Suppl 1:59-74. doi: 10.1111/jnc.13593.

36. Armstrong MJ, Okun MS. Diagnosis and Treatment of Parkinson Disease: A Review. Jama. 2020;323:548-60. doi: 10.1001/ jama.2019.22360.

37. Berg D, Postuma RB, Adler CH, Bloem BR, Chan P, Dubois B, et al. MDS research criteria for prodromal Parkinson's disease. Mov Disord. 2015;30:1600-11. doi: 10.1002/mds.26431.

38. Brys M, Fanning L, Hung S, Ellenbogen A, Penner N, Yang M, et al. Randomized phase I clinical trial of anti-alpha-synuclein antibody BIIB054. Mov Disord. 2019;34:1154-63. doi: 10.1002/mds.27738.

39. Jankovic J. Parkinson's disease: clinical features and diagnosis. J Neurol Neurosurg Psychiatry. 2008;79:368-76. doi: 10.1136/ jnnp.2007.131045.

40. McGregor MM, Nelson AB. Circuit Mechanisms of Parkinson's Disease. Neuron. 2019;101:1042-56. doi: 10.1016/j.neuron.2019.03.004.

41. Greffard S, Verny M, Bonnet AM, Beinis JY, Gallinari C, Meaume $\mathrm{S}$, et al. Motor score of the Unified Parkinson Disease Rating Scale as a good predictor of Lewy body-associated neuronal loss in the substantia nigra. Arch Neurol. 2006;63:584-8. doi: 10.1001/ archneur.63.4.584.

42. Seidel K, Mahlke J, Siswanto S, Kruger R, Heinsen H, Auburger G, et al. The brainstem pathologies of Parkinson's disease and dementia with Lewy bodies. Brain Pathol. 2015;25:121-35. doi: 10.1111/ bpa.12168.

43. Low PA, Reich SG, Jankovic J, Shults CW, Stern MB, Novak P, et al. Natural history of multiple system atrophy in the USA: a prospective cohort study. Lancet Neurol. 2015;14:710-9. doi: 10.1016/S14744422(15)00058-7.

44. Wenning GK, Ben Shlomo Y, Magalhaes M, Daniel SE, Quinn NP. Clinical features and natural history of multiple system atrophy. An analysis of 100 cases. Brain. 1994;117 ( Pt 4):835-45. doi: 10.1093/ brain/117.4.835.

45. Fanciulli A, Wenning GK. Multiple-system atrophy. N Engl J Med. 2015;372:249-63. doi: 10.1056/NEJMra1311488.

46. Palma JA, Norcliffe-Kaufmann L, Kaufmann H. Diagnosis of multiple system atrophy. Auton Neurosci. 2018;211:15-25. doi: 10.1016/j. autneu.2017.10.007.

47. Kaufmann H, Norcliffe-Kaufmann L, Palma JA, Biaggioni I, Low PA, Singer W, et al. Natural history of pure autonomic failure: A United States prospective cohort. Ann Neurol. 2017;81:287-97. doi: 10.1002/ ana. 24877 .

48. O'Sullivan SS, Massey LA, Williams DR, Silveira-Moriyama L, Kempster $\mathrm{PA}$, Holton $\mathrm{JL}$, et al. Clinical outcomes of progressive supranuclear palsy and multiple system atrophy. Brain. 2008;131:1362-72. doi: 10.1093/brain/awn065.

49. Tong J, Wong H, Guttman M, Ang LC, Forno LS, Shimadzu M, et al. Brain alpha-synuclein accumulation in multiple system atrophy, Parkinson's disease and progressive supranuclear palsy: a comparative investigation. Brain. 2010;133:172-88. doi: 10.1093/brain/awp282.

50. Jellinger KA, Lantos PL. Papp-Lantos inclusions and the pathogenesis of multiple system atrophy: an update. Acta Neuropathol. 2010;119:657-67. doi: 10.1007/s00401-010-0672-3.

51. Shults CW, Rockenstein E, Crews L, Adame A, Mante M, Larrea G, et al. Neurological and neurodegenerative alterations in a transgenic mouse model expressing human alpha-synuclein under oligodendrocyte promoter: implications for multiple system atrophy. J Neurosci. 2005;25:10689-99. doi: 10.1523/JNEUROSCI.3527-05.2005.

52. Goldstein DS, Sullivan P, Holmes C, Mash DC, Kopin IJ, Sharabi Y. Determinants of denervation-independent depletion of putamen dopamine in Parkinson's disease and multiple system atrophy. Parkinsonism Relat Disord. 2017;35:88-91. doi: 10.1016/j.parkreldis.2016.12.011.

53. Kahle PJ, Haass C, Kretzschmar HA, Neumann M. Structure/function of alpha-synuclein in health and disease: rational development of animal models for Parkinson's and related diseases. Journal of neurochemistry. 2002;82:449-57. doi: 10.1046/j.1471-4159.2002.01020.x.

54. Ubhi K, Rockenstein E, Mante M, Inglis C, Adame A, Patrick C, et al. Neurodegeneration in a transgenic mouse model of multiple system atrophy is associated with altered expression of oligodendroglial-derived neurotrophic factors. J Neurosci. 2010;30:6236-46. doi: 10.1523/JNEUROSCI.0567-10.2010

55. Goldstein DS, Sullivan P, Holmes C, Bankiewicz K. Post-mortem and in vivo evidence for "sick but not dead" central dopaminergic neurons in multiple system atrophy: implications for neurotrophic factor gene enhancement therapy (Poster Abstract). 30TH INTERNATIONAL SYMPOSIUM ON THE AUTONOMIC NERVOUS SYSTEM. Clearwater Beach, Florida: Clin Auton Res - Springer; 2019. p. 34 in https://doi. org/10.1007/s10286-019-00631-x.

56. Du Y, Dreyfus CF. Oligodendrocytes as providers of growth factors. J Neurosci Res. 2002;68:647-54. doi: 10.1002/jnr.10245.

57. Pascual A, Hidalgo-Figueroa M, Piruat Jl, Pintado CO, Gomez-Diaz R, Lopez-Barneo J. Absolute requirement of GDNF for adult catecholaminergic neuron survival. Nat Neurosci. 2008;11:755-61. doi: 10.1038/ nn.2136.

58. Nutt JG, Burchiel KJ, Comella CL, Jankovic J, Lang AE, Laws ER, Jr., et al. Randomized, double-blind trial of glial cell line-derived neurotrophic factor (GDNF) in PD. Neurology. 2003;60:69-73. doi: 10.1212/ WNL.60.1.69.

59. Patel NK, Gill SS. GDNF delivery for Parkinson's disease. Acta Neurochir Suppl. 2007;97:135-54. doi: 10.1007/978-3-211-33081-4_16.

60. Gill SS, Patel NK, Hotton GR, O'Sullivan K, McCarter R, Bunnage M, et al. Direct brain infusion of glial cell line-derived neurotrophic factor in Parkinson disease. Nat Med. 2003;9:589-95. doi: 10.1038/nm850.

61. Whone A, Luz M, Boca M, Woolley M, Mooney L, Dharia S, et al. Randomized trial of intermittent intraputamenal glial cell line-derived neurotrophic factor in Parkinson's disease. Brain. 2019;142:512-25. doi: 10.1093/brain/awz023.

62. Whone AL, Boca M, Luz M, Woolley M, Mooney L, Dharia S, et al. Extended Treatment with Glial Cell Line-Derived Neurotrophic Factor in Parkinson's Disease. J Parkinsons Dis. 2019;9:301-13. doi: 10.3233/JPD-191576.

63. Hadaczek P, Johnston L, Forsayeth J, Bankiewicz KS. Pharmacokinetics and bioactivity of glial cell line-derived factor (GDNF) and neurturin (NTN) infused in rat brain. Neuropharmacol. 2010;58:1114-21. doi: 10.1016/j.neuropharm.2010.02.002.

64. Yin D, Valles FE, Fiandaca MS, Forsayeth J, Larson P, Starr P, et al. Striatal volume differences between non-human and human primates. J Neurosci Methods. 2009;176:200-5. doi: 10.1016/j. jneumeth.2008.08.027.

65. Marks WJ, Jr., Bartus RT, Siffert J, Davis CS, Lozano A, Boulis N, et al. Gene delivery of AAV2-neurturin for Parkinson's disease: a double-blind, randomised, controlled trial. Lancet Neurol. 2010;9:1164-72. doi: 10.1016/S1474-4422(10)70254-4.

66. Mittermeyer G, Christine CW, Rosenbluth KH, Baker SL, Starr P, Larson $\mathrm{P}$, et al. Long-term evaluation of a phase 1 study of AADC gene therapy 
for Parkinson's disease. Human gene therapy. 2012;23:377-81. doi: 10.1089/hum.2011.220.

67. Bartus RT, Baumann TL, Siffert J, Herzog CD, Alterman R, Boulis N, et al. Safety/feasibility of targeting the substantia nigra with AAV2-neurturin in Parkinson patients. Neurology. 2013;80:1698-701. doi: 10.1212/WNL.0b013e3182904faa.

68. Chu Y, Bartus RT, Manfredsson FP, Olanow CW, Kordower JH. Long-term post-mortem studies following neurturin gene therapy in patients with advanced Parkinson's disease. Brain. 2020;143:960-75. doi: 10.1093/brain/awaa020.

69. Valles F, Fiandaca MS, Bringas J, Dickinson P, LeCouteur R, Higgins $\mathrm{R}$, et al. Anatomic compression caused by high-volume convection-enhanced delivery to the brain. Neurosurgery. 2009;65:579-85; discussion 85-6. doi: 10.1227/01.NEU.0000350229.77462.2F.

70. Fiandaca MS, Bankiewicz KS. Gene therapy for Parkinson's disease: from non-human primates to humans. Curr Opin Mol Ther. 2010;12:519-29. https://europepmc.org/article/med/20886383.

71. Axelsen TM, Woldbye DPD. Gene Therapy for Parkinson's Disease, An Update. J Parkinsons Dis. 2018;8:195-215. doi: 10.3233/JPD181331.

72. Wu Z, Asokan A, Samulski RJ. Adeno-associated virus serotypes: vector toolkit for human gene therapy. Mol Ther. 2006;14:316-27. doi:10.1016/j.ymthe.2006.05.009.

73. Wong LF, Goodhead L, Prat C, Mitrophanous KA, Kingsman SM, Mazarakis ND. Lentivirus-mediated gene transfer to the central nervous system: therapeutic and research applications. Hum Gene Ther. 2006;17:1-9. doi: 10.1089/hum.2006.17.1.

74. Cronin J, Zhang XY, Reiser J. Altering the tropism of lentiviral vectors through pseudotyping. Current gene therapy. 2005;5:387-98. doi: 10.2174/1566523054546224.

75. Brat DJ. Normal Brain Histopathology. Practical Surgical Neuropathology: A Diagnostic Approach: Elsevier Inc.; 2010. p. 15-33. doi: 10.1016/B978-0-443-06982-6.00002-X.

76. Sato K, Kaji R, Matsumoto S, Nagahiro S, Goto S. Compartmental loss of striatal medium spiny neurons in multiple system atrophy of parkinsonian type. Mov Disord. 2007;22:2365-70. doi: 10.1002/mds.21732.

77. Wu Z, Yang H, Colosi P. Effect of genome size on AAV vector packaging. Mol Ther. 2010;18:80-6. doi: 10.1038/mt.2009.255.

78. Kumar M, Keller B, Makalou N, Sutton RE. Systematic determination of the packaging limit of Ientiviral vectors. Hum Gene Ther. 2001;12:1893-905. doi: 10.1089/104303401753153947.

79. Christine CW, Starr PA, Larson P, Mah R, Eberling J, Jagust W, et al. Aromatic L-Amino Acid Decarboxylase Gene Transfer Therapy for Parkinson's Disease: Initial Results of an Open-Label, Dose Escalation, Safety and Tolerability Study. Abstract S23.005. American Academy of Neurology. San Diego, CA2006.

80. Christine CW, Starr PA, Larson PS, Eberling JL, Jagust WJ, Hawkins RA, et al. Safety and tolerability of putaminal AADC gene therapy for Parkinson disease. Neurology. 2009;73:1662-9. doi: 10.1212/ WNL.0b013e3181c29356.

81. Palfi S, Gurruchaga JM, Ralph GS, Lepetit H, Lavisse S, Buttery PC, et al. Long-term safety and tolerability of ProSavin, a lentiviral vector-based gene therapy for Parkinson's disease: a dose escalation, open-label, phase 1/2 trial. Lancet. 2014;383:1138-46. doi: 10.1016/ S0140-6736(13)61939-X.

82. Bankiewicz KS, Forsayeth J, Eberling JL, Sanchez-Pernaute R, Pivirotto $\mathrm{P}$, Bringas J, et al. Long-term clinical improvement in MPTP-lesioned primates after gene therapy with AAV-hAADC. Mol Ther. 2006;14:56470. doi: 10.1016/j.ymthe.2006.05.005.
83. Forsayeth JR, Eberling JL, Sanftner LM, Zhen Z, Pivirotto P, Bringas J, et al. A dose-ranging study of AAV-hAADC therapy in Parkinsonian monkeys. Mol Ther. 2006;14:571-7. doi: 10.1016/j.ymthe.2006.04.008.

84. Kaplitt MG, Feigin A, Tang C, Fitzsimons HL, Mattis P, Lawlor PA, et al. Safety and tolerability of gene therapy with an adeno-associated virus (AAV) borne GAD gene for Parkinson's disease: an open label, phase I trial. Lancet. 2007;369:2097-105. doi:10.1016/S01406736(07)60982-9.

85. LeWitt PA, Rezai AR, Leehey MA, Ojemann SG, Flaherty AW, Eskandar EN, et al. AAV2-GAD gene therapy for advanced Parkinson's disease: a double-blind, sham-surgery controlled, randomised trial. Lancet Neurol. 2011;10:309-19. doi: 10.1016/S1474-4422(11)70039-4.

86. Niethammer M, Tang CC, Vo A, Nguyen N, Spetsieris P, Dhawan V, et al. Gene therapy reduces Parkinson's disease symptoms by reorganizing functional brain connectivity. Sci TransI Med. 2018;10. doi: 10.1126/ scitransImed.aau0713.

87. Olanow CW, Bartus RT, Baumann TL, Factor S, Boulis N, Stacy M, et al. Gene delivery of neurturin to putamen and substantia nigra in Parkinson disease: A double-blind, randomized, controlled trial. Ann Neurol. 2015;78:248-57. doi: 10.1002/ana.24436.

88. Marks WJ, Jr., Baumann TL, Bartus RT. Long-Term Safety of Patients with Parkinson's Disease Receiving rAAV2-Neurturin (CERE120) Gene Transfer. Hum Gene Ther. 2016;27:522-7. doi: 10.1089/ hum.2015.134.

89. Bartus RT, Brown L, Wilson A, Kruegel B, Siffert J, Johnson EM, Jr., et al. Properly scaled and targeted AAV2-NRTN (neurturin) to the substantia nigra is safe, effective and causes no weight loss: support for nigral targeting in Parkinson's disease. Neurobiol Dis. 2011;44:38-52. doi: 10.1016/j.nbd.2011.05.026.

90. Bartus RT, Herzog CD, Chu Y, Wilson A, Brown L, Siffert J, et al. Bioactivity of AAV2-neurturin gene therapy (CERE-120): differences between Parkinson's disease and nonhuman primate brains. Mov Disord. 2011;26:27-36. doi: 10.1002/mds.23442.

91. Bartus RT, Kordower JH, Johnson EM, Jr., Brown L, Kruegel BR, Chu Y, et al. Post-mortem assessment of the short and long-term effects of the trophic factor neurturin in patients with alpha-synucleinopathies. Neurobiol Dis. 2015;78:162-71. doi: 10.1016/j.nbd.2015.03.023.

92. Olanow CW, Bartus RT, Volpicelli-Daley LA, Kordower JH. Trophic factors for Parkinson's disease: To live or let die. Mov Disord. 2015;30:171524. doi: 10.1002/mds.26426.

93. Kells AP, Eberling J, Su X, Pivirotto P, Bringas J, Hadaczek P, et al. Regeneration of the MPTP-lesioned dopaminergic system after convection-enhanced delivery of AAV2-GDNF. J Neurosci. 2010;30:9567-77. doi: 10.1523/JNEUROSCI.0942-10.2010.

94. Bankiewicz KS, Sudhakar V, Samaranch L, San Sebastian W, Bringas J, Forsayeth J. AAV viral vector delivery to the brain by shape-conforming MR-guided infusions. J Control Release. 2016;240:434-42. doi: 10.1016/j.jconrel.2016.02.034.

95. Wassenberg T, Molero-Luis M, Jeltsch K, Hoffmann GF, Assmann B, Blau N, et al. Consensus guideline for the diagnosis and treatment of aromatic l-amino acid decarboxylase (AADC) deficiency. Orphanet J Rare Dis. 2017;12:12. doi: 10.1186/s13023-016-0522-z.

96. Chien YH, Lee NC, Tseng SH, Tai CH, Muramatsu SI, Byrne BJ, et al. Efficacy and safety of AAV2 gene therapy in children with aromatic L-amino acid decarboxylase deficiency: an open-label, phase 1/2 trial. Lancet Child Adolesc Health. 2017;1:265-73. doi: 10.1016/S23524642(17)30125-6.

97. Hadaczek P, Eberling JL, Pivirotto P, Bringas J, Forsayeth J, Bankiewicz KS. Eight years of clinical improvement in MPTP-lesioned primates 
after gene therapy with AAV2-hAADC. Mol Ther. 2010;18:1458-61. doi: 10.1038/mt.2010.106.

98. Hadaczek P, Wu G, Sharma N, Ciesielska A, Bankiewicz K, Davidow AL, et al. GDNF signaling implemented by GM1 ganglioside; failure in Parkinson's disease and GM1-deficient murine model. Exp Neurol. 2015;263:177-89. doi: 10.1016/j.expneurol.2014.10.010.

99. Castle MJ, Baltanas FC, Kovacs I, Nagahara AH, Barba D, Tuszynski MH. Postmortem Analysis in a Clinical Trial of AAV2-NGF Gene Therapy for Alzheimer's Disease Identifies a Need for Improved Vector Delivery. Hum Gene Ther. 2020. Epub 2020/03/05 doi: 10.1089/ hum.2019.367.

100. Neurosurgery US. Statement of the American Association of Neurological Surgeons American, Board of Neurological Surgery, Congress of Neurological Surgeons, and Society of Neurological Surgeons, before the Institute of Medicine On the Subject of Ensuring an Adequate Neurosurgical Workforce for the 21st Century https://www.aans. org/pdf/Legislative/Neurosurgery\%20IOM\%20GME\%20Paper\%20 12\%2019\%2012.pdf. Washington, D.C.: Neurosurgery.org; 2012.

101. Mukhopadhyay S, Punchak M, Rattani A, Hung YC, Dahm J, Faruque $S$, et al. The global neurosurgical workforce: a mixed-methods assessment of density and growth. J Neurosurg. 2019:1-7. doi: 10.3171/2018.10.JNS171723.

102. Madhavan K, Kolcun JPG, Chieng LO, Wang MY. Augmented-reality integrated robotics in neurosurgery: are we there yet? Neurosurg Focus. 2017;42:E3. doi: 10.3171/2017.2.FOCUS177.

103. Wang MY, Goto T, Tessitore E, Veeravagu A. Introduction. Robotics in neurosurgery. Neurosurg Focus. 2017;42:E1. doi: 10.3171/2017.2.FOCUS1783.

104. Smith JA, Jivraj J, Wong R, Yang V. 30 Years of Neurosurgical Robots: Review and Trends for Manipulators and Associated Navigational Systems. Ann Biomed Eng. 2016;44:836-46. doi: 10.1007/s10439015-1475-4.

105. Senders JT, Arnaout O, Karhade AV, Dasenbrock HH, Gormley WB, Broekman ML, et al. Natural and Artificial Intelligence in Neurosurgery: A Systematic Review. Neurosurgery. 2018;83:181-92. doi: 10.1093/neuros/nyx384.

106. Hollon TC, Pandian B, Adapa AR, Urias E, Save AV, Khalsa SSS, et al. Near real-time intraoperative brain tumor diagnosis using stimulated Raman histology and deep neural networks. Nat Med. 2020;26:52-8. doi: 10.1038/s41591-019-0715-9. 